REVIEW ARTICLE

\title{
Pandemics and epidemics: Past, present and future
}

\author{
Jennifer Perera ${ }^{1}$ \\ ${ }^{1}$ Emeritus Professor, Department of Medical Microbiology and Immunology, Faculty of Medicine, University of Colombo, Sri Lanka
}

\author{
Article Information \\ Total number of \\ Words 4283 \\ Author have no conflicts of interest to \\ declare
}

Keywords: Pandemics, epidemics, history, preparedness, integrated surveillance

Date of submission: 2021-04-30

Date of acceptance: 2021-09-28

Author responsible for correspondence: Jennifer Perera

Emeritus Professor, Department of

Medical Microbiology and

Immunology, Faculty of Medicine,

University of Colombo, Sri Lanka

Email: jenniferp@micro.cmb.ac.lk

DOI: http://doi.org/10.4038/cjms.v57i1.5017

iD https://orcid.org/0000-0002-7450-5672

\begin{abstract}
There have been many significant disease outbreaks and pandemics recorded in history. With rapidly changing ecology, urbanization, climate change, increased travel and outdated public health systems, epidemics and pandemics will become more frequent, more complex and harder to prevent and contain. Many features of a pandemic, including the geographic extension, novelty, severity, minimal population immunity and infectiousness determines the outcome. The pandemic related crises have been associated with enormous negative impacts on health, economy, society and security of national and global communities. They have led to significant political and social disruption. Research indicate that disadvantaged nations and certain groups of people or societies are affected most during pandemics. The great majority of the more recent epidemics and pandemics were zoonotic and some related to wildlife. Being better prepared for pandemics could mitigate its impact on the world as a whole. The preparedness plans should include comprehensive surveillance systems on wildlife to identify the carriage of high-risk pathogens, people who have contact with wild life to identify early spillover events and market biosecurity regarding the wildlife trade. Use of advances in computer science, artificial intelligence and data science need to be actively integrated when planning epidemic responses. The use of 'One Health' approach will enable earlier response. Pharmaceutical interventions such as vaccines and antiviral agents are less likely to be available in developing countries. Furthermore, the public health and clinical infrastructure of developing countries are often inadequate to deal with a widespread health crisis which will in turn inevitably affect the global health. Thus, an integrated global effort is required to prevent future epidemics and pandemics.
\end{abstract}

\section{Introduction}

Pandemics or plagues, as they are often referred to, have had a great impact on shaping the history and civilization of the world and developments in modern health sciences. Stemming from the Greek word "plaga” (strike, blow), the word "plague" is used to describe the infectious, febrile epidemic disease causing a high rate of mortality or other serious outcomes [1]. This review attempts to provide a broad overview of major outbreaks and pandemics of the past, the current COVID-19 pandemic, major implications, possible reasons for occurrence of pandemics and lessons for the future.

\section{History of pandemics and outbreaks}

Plague

The best known examples of plagues recorded in ancient times are perhaps, those referred to in the Old Testament. 
Book of Exodus, mentions a series of ten plagues that struck the Egyptians before the Israelites who were held in captivity by the Pharaoh, the ruler of Egypt, were finally released. Some of them were clearly infectious and were related to lice, diseased livestock and skin boils etc. When examined through the lens of spirituality, these outbreaks were often interpreted as "divine punishments for sins".

The Athenian plague is a historically documented event that occurred in 430- 26 B.C., during the Peloponnesian War, battled between the cities of Athens and Sparta. The plague is thought to have originated in Ethiopia and spread through Greece and Egypt [2]. Initial symptoms of the plague included headaches, conjunctivitis, a generalized rash, and fever. They had haemoptysis, and suffered from severe abdominal pain and vomiting and died by the $7^{\text {th }}$ or $8^{\text {th }}$ day. The doctors and other caregivers frequently got infected and died. The plague of Athens had claimed lives of more than $25 \%$ of the population in the city [3]. The cause of the Athenian plague has not been clearly determined, but the recent theory postulated by epidemiologists considers it to be Ebola virus haemorrhagic fever [4].

Plague caused by Yersinia pestis is a zoonotic infection and is maintained in wildlife mainly by rodent reservoirs and occasionally transmitted to human populations causing outbreaks. The Justinian plague in ancient Rome, originated either in Ethiopia or Central Asia in $6^{\text {th }}$ century $\mathrm{AD}$ (541- $549 \mathrm{AD}$ ). It is thought to have travelled along the caravan trading routes and specially affected coastal cities [5]. The symptoms included fever and fatigue with lumps in groins and armpits which later became gangrenous. Those affected died within days. It is stated that Emperor Justinian contracted the plague, but did not succumb [6]. It is reported that within a short time that all gravesites were filled beyond capacity and the bodies were piled along the seashore leading to a bad stench. Streets had been deserted and trade was abandoned, and people appear to have died of either starvation or the disease [7].

The Black Death or Plague was a pandemic of bubonic plague that commenced in 1347 and spread to Europe and then to Russia and the Middle East along the Silk Road [8]. This disease has had significant demographic, social, and economic consequences, and has remained in Europe for over 300 years, disappearing intermittently. There had been 20-30 epidemics of plague during this period in various locations [9]. It reduced the global population from about 450 million to below 300 million [10]. In predominantly Catholic Europe the cause was interpreted as "punishment for sins", and minorities (e.g Jews) and women have been marginalised as "gravest sinners" [11]. The only remedies used were inhalation of aromatic vapors from flowers or camphor. Soon, there had been a proliferation of quacks selling useless cures that claimed to offer magical protection [12] as is observed even today, during this current pandemic due to SARS-Cov-2 virus. The plague had broken down the normal divisions between the upper and lower classes which caused the emergence of a new middle class. The scarcity of labor due to high number of deaths encouraged innovation and development of labor-saving technologies, leading to higher productivity [13]. During this time, there had been a shortage of doctors and governments contracted young doctors to perform the duty of a plague doctor. The attire of the doctor resembled the current personal protective equipment and comprised a mask with a long beak and a leather costume covering the full body as shown in a $17^{\text {th }}$ century painting [14]. Even during this time, when dealing with contagious diseases, they have instituted mandatory isolation. The first recorded quarantine was enacted in Ragusa in 1377 where all arrivals to the city had to spend 30 days in a nearby island before entering the city [15].

The third major epidemic of plague, originated in China in 1855 and spread throughout the world. Lasting until 1859, it caused 15 million deaths, the majority being in India. Yersinia pestis is found in enzootic foci on every inhabited continent. With regard to the most recently reported epidemic of plague with over a hundred pneumonic plague cases was in Congo from 2004 and 2005 [16, 17]. It appears that plague will continue to cause outbreaks in conducive environments.

\section{Influenza}

Spanish flu pandemic caused by the H1N1 influenza virus appeared in 1918 and continued until 1920. This is the first global pandemic in its truest sense in the setting of modern medicine when specialties such as infectious diseases and epidemiology developed. This pandemic took place during the World War 1 and the definite place of origin remains unknown to date [18]. The massive military movements, overcrowding, intercontinental travel facilitated the global spread of the disease within months. Over quarter of the global population contracted the disease and had $10 \%$ to $20 \%$ mortality. Spanish flu killed over 50 million which is more than the number of deaths due to Black Death [19]. Spanish flu influenced the outcome of World War 1 as certain armies were affected more than the others.

Sri Lanka too was affected by the flu pandemic of 1918 . Influenza possibly entered the country through the port of Colombo and the port of Talaimannar. As elsewhere, initially there was a mild first wave followed by a more severe second wave characterized by fatal pneumonic complications. Heavy mortality was observed in women than men and young adults more than other age groups. During this period almost $1.1 \%$ of the population died [20].

Swine flu or H1N1/09 influenza pandemic in 2009 was a repeat of 1918 Spanish flu, but had far less harmful 
consequences. This was suspected to be a re-assortment of bird, swine and human flu viruses. It started in Mexico in April of 2009 and reached to pandemic extents within weeks but was controlled within a year, by May 2010. It infected about $10 \%$ of the global population with an estimated death toll varying from 20,000 to 50,000 [21]. Previously, healthy young individuals were affected more severely than the older age groups and immunity gained by older persons through a previous exposure to a similar HIN1 virus in 1970s was thought to be a plausible explanation. During this epidemic, WHO released warnings which did not match the outcome as the infection was controlled and the general public accused health agencies of causing unnecessary panic [22]. This could be a possible reason for the hesitancy showed by WHO in declaring SRS-Cov2 disease a pandemic, until quite late. This experience shows the difficulty in managing public expectations when making efforts to mobilize a public response.

\section{Smallpox}

Smallpox caused by the variola virus was a highly infectious disease and, the first vaccine developed was against smallpox in 1798 by Edward Jenner. Smallpox is thought to have originated in Egypt or India around 3000 years ago. The pandemic outbreak was first reported in Eastern Nigeria, in December 1966 and spread to other parts of the world. The bifurcated needle developed in 1961 was used as the primary instrument in vaccine-based eradication campaign from 1966 to 1977 [23].

The disease characterized with a generalized pustular rash had approximately 30\% mortality. However, due to the wellcoordinated global public health efforts, the disease was controlled and eradicated within a decade.

Historically, the Antonian plague that occurred in the Roman Empire, during the reign of Marcus Aurelius (161180 A.D.) is believed to be due to smallpox [24]. It was brought into the Roman Empire by soldiers returning from Seleucia and reported to have destroyed about one third of its population and claimed the life of Marcus Aurelius [25].

More recently a smallpox outbreak occurred in former Yugoslavia in 1972, brought in by a pilgrim returning from the Middle East. The physicians failed to diagnose the illness and 9 healthcare workers got infected [26]. The Yugoslavia introduced mandatory revaccination and entire geographic regions were placed on quarantine, borders were closed, and martial law was declared. Within 2 weeks the entire population of 18 million were revaccinated and the society recovered to normal within 2 months. This has proven to be a useful model for controlling highly contagious diseases and has found its relevance during the current pandemic too.

\section{Cholera}

The cause of cholera, Vibrio cholerae, was detected and described by Robert Koch in 1883, when he was sent out as a leader of a commission to Egypt and India to investigate the cause of cholera. Two biotypes of $V$. cholerae have caused the pandemics, the classical strain and the El Tor strain, both of O1 serotype. By about 1990s a new 0139 serotype was discovered as a cause of cholera [27]. There have been 8 pandemics of cholera and each of them continued for many years. The classical O1 biotype was responsible for the first six pandemics from 1817-1923, while the El Tor biotype caused the $7^{\text {th }}$ pandemic, 1961present, and the $\mathrm{O} 139$ for the $8^{\text {th }}$ pandemic (Bengal) 1992 present [28].

\section{Human Immunodeficiency Virus (HIV) disease}

HIV caused a slowly progressing pandemic that cascaded over decades. It started in early 1980s in the USA, causing much concern as it inevitably progressed to AIDS and death. The initial HIV outbreak was characterized by its spread predominantly among the gay population and by high mortality, leading to marked social isolation and stigma. Later, it was identified as an equally important disease among people with heterosexual partners. HIV has so far affected 40 million people globally and has a prevalence rate of $0.79 \%$. It has killed 40 million since 1981 and causes one million deaths annually [29]. Currently, it is particularly affecting some African countries where prevalence is about $25 \%$ [30].

HIV spreads slowly and thus drew the attention of not only public health institutions, but pharmaceutical industry as well. Advances in treatment reduced deaths due to HIV disease markedly and it has now become a chronic disease which can be managed by medication.

\section{Severe Acute Respiratory Syndrome}

Severe Acute Respiratory Syndrome (SARS) was first reported in February 2003 and was the first outbreak in the 21st century that received global attention [31]. The outbreak was linked to a health worker from Guangdong Province, China, who visited Hong Kong and stayed in a hotel from where he was hospitalized with severe pneumonia and died. The disease eventually spread to Vietnam, Singapore, Thailand, Hong Kong, Canada, Taiwan, and the United States. This was caused by a corona virus that originated in China and affected approximately 10,000 individuals mainly in China and Hong Kong and infected many healthcare workers and family members of patients [32]. It had a 10\% mortality rate, and the outbreak was controlled in mid-2003 due to effective public health measures which prevented it becoming a pandemic [33]. 


\section{Middle East Respiratory Syndrome}

Middle East respiratory syndrome coronavirus (MERS$\mathrm{CoV}$ ) was discovered for the first time in Saudi Arabia in 2012 [34]. The World Health Organization (WHO) has confirmed 2574 cases of human infections with MERSCoV in 27 countries since 2012 to 2019; 885 (34.4\%) infected patients have died by the end of March 2021. Saudi Arabia has reported the highest reported MERS$\mathrm{CoV}$ deaths. Approximately $80 \%$ of the cases have been reported to occur in Saudi Arabia [35]. Although bats are the main reservoir for most coronaviruses, dromedary camels are considered the only known reservoir for MERS$\mathrm{CoV}$ to date. However, it is known that MERS-CoV isolated from dromedary camels is closely related to some bat coronaviruses [36]. According to the WHO, MERS-CoV transmission between humans is possible and has occurred in Middle East countries and the Republic of Korea [34]. The viral spread has been observed among health-care workers and people visiting MERS-CoVpositive patients. Immunocompromised individuals as well as patients with comorbidities are most prone to severe MERS-CoV infection, which has led to death of these infected patients [37].

\section{Ebola virus disease}

Ebola virus outbreaks have occurred in Central and West Africa from time to time. The largest Ebola virus outbreak occurred from 2013 to 2016 in Central and West Africa with a few cases being reported in Europe and North America [38]. The fruit bats were identified as the likely source. The largest outbreak commenced in Guinea in December 2013 and spread mostly within families and reached neighboring countries, Sierra Leonne and Liberia. The outbreak was characterized by a high mortality with over 28,000 cases and over 11,000 deaths [39].

\section{Zika virus disease}

Zika virus is a mosquito-borne flavivirus that was first identified in Uganda in 1947 in monkeys. It was later identified in humans in 1952 in Uganda and the United Republic of Tanzania. Sporadic cases of Zika virus disease have been recorded in Africa, the Americas, Asia and the Pacific from the 1960 s to 1980 s.

The first recorded outbreak of Zika virus disease was from the Island of Yap in 2007. This was followed by a large outbreak of Zika virus infection in French Polynesia in 2013. In March 2015, Brazil reported a large outbreak comprising an illness with fever and a rash, which was soon identified as Zika virus infection. In July 2015, it was found to be associated with the Guillain-Barré syndrome. In October 2015, Brazil reported an association between Zika virus infection and microcephaly. Outbreaks and evidence of transmission soon appeared throughout America, Africa, and other regions of the world. To date, a total of 86 countries have reported evidence of mosquitotransmitted Zika infection [40]. This was also the first time, social media were heavily involved in an infectious disease outbreak, either to disseminate information or to express concerns. However fake news occurred at the rate of 1 out of 5 posts and needed significant attention during preparedness plans and execution of public health programmes [41]. Since 2016 it has continued to spread in Americas and there is no vaccine against Zika virus to date. Sri Lanka is at risk of acquiring this disease as the vector Aedes mosquito is ubiquitous in the island.

\section{Severe Acute Respiratory Virus (SARS Cov-2) disease (Covid-19)}

Over the past two decades, the emergence of coronavirusassociated diseases (SARS and MERS) caused global challenges to public health systems. SARS-CoV-2 (the causative agent of coronavirus disease COVID-19) is the latest addition to this growing list of unwelcome novel coronaviruses.

The WHO declared COVID-19 a public health emergency of international concern on $30^{\text {th }}$ January 2020 and a pandemic on $11^{\text {th }}$ March 2020. The current COVID-19 pandemic where the appearance of a cluster of cases of pneumonia linked to a sea food market in Wuhan, China, has become one of the worst pandemics in human history with a staggering number of more than 144 million confirmed cases, in 223 countries and 3,066,113 deaths globally as of $23^{\text {rd }}$ April 2021 [42].

COVID-19 is a respiratory illness with a clinical spectrum of mild to moderate disease (80\%), severe disease (15\%), and critical illness (5\%). It has an overall case fatality rate of 0.5-2.8 \%, with much higher rates (3.7-14.8\%) in octogenarians. The severe and critical illness categories (about 20\% of all infections) have overwhelmed health systems worldwide. SARS-CoV-2, the agent of COVID19 , primarily spreads by droplets and droplet nuclei, is easily transmissible (reproduction number R0: 2-3, meaning one infected individual could infect three), and can spread through asymptomatic or minimally symptomatic individuals. It has a median incubation period of five-tosix days and a period of infectivity extending from two days before symptom onset to two weeks after disease onset in severe cases [43].

Pending availability of an effective vaccine, proactive containment strategies e.g use of face masks, travel restrictions, case finding, contact tracing, isolation of confirmed cases, quarantine of exposed individuals, lockdown measures, social distancing, school and educational institutions closures, and postponement or cancellation of large-scale public gatherings were used extensively all over the globe to control this pandemic and continues to date with their relaxation from time to time, being carefully planned $[44,45]$. 
Unlike in the previous pandemics, the vaccine industry expedited development of vaccines which was instrumental in controlling the pandemic to a great degree and the challenges posed by the large number of evolving variants from all over the world appears to be hampering the control of SARS Cov 2 at present. As of 26 April 2021, a total of 933,824,012 vaccine doses have been administered [41].

However, due to the appearance of new SARS-CoV-2 variants, there could be repeated outbreaks and recurrences [46]. SARS-CoV-2 can probably never be globally eradicated. Due to incomplete vaccine coverage and variable degrees of immunological protection, ongoing strategies to deal with the endemic presence of SARSCoV-2 may be needed. Furthermore, data on requirement for revaccination with current or new COVID-19 vaccines will be required since the duration of immunological protection and the efficacy against emergent SARS-CoV2 variants remain unknown.

During this current outbreak, many other aspects related to holistic health surfaced. Little attention had been given in the past to study the mental health of individuals and communities affected by pandemics. The SARS outbreak was among the first acute outbreaks that had mental health aspects studied in different societies. The studies provided valuable data on mental health effects of an outbreak of an acute infection on affected individuals, families, and the entire communities, including the mental health issues faced by healthcare providers [47]. When COVID-19 struck the world, the mental health problems experienced were not limited to infected persons but also extended to involve frontline health workers and community members alike [48]. Many universities and schools worldwide have moved to emergency remote teaching (ERT) via online platforms, causing anxiety among the students [49]. To address these issues both mental and behavioural health interventions were recommended in public health response strategies [50].

Most countries responded to the pandemic by social distancing measures which in turn drastically diminished economic and other activities. Consequently, the COVID19 pandemic has led to numerous environmental impacts, both positive and negative outcomes, such as enhanced air and water quality in urban areas and increased pollution due to the disposal of plastic consumables used in health services [51].

Bioethical implications were many during the current pandemic and were related to the attempts to protect the lives and disbursement of resources. These require prioritising choices made on the sick hospitalized in health facilities and is challenging when resources are limited [52]. The main priority that needs to be adopted is the "clinical criterion" and the use of all available, instrumental and professional resources based on it. An important bioethical implication concerns the attention and care of the elderly, chronically ill, disabled and terminally ill. The clinical criteria always need to be correlated to the principles of equality and justice. Exclusion of choices based only on age and past critical issues could have serious repercussions for the elderly, the multi-systemic chronically ill and the disabled and are to be discouraged.

Though domestic violence is recognized among both men and women, women are predominantly affected. A recent report of WHO has assessed that one third of women all over the world are enduring domestic violence. Pandemics that lead to economic disruptions, isolation through frequent lockdowns, closure of schools, poor access to voluntary services, economic vulnerability, and challenges to the healthcare responses have amplified domestic violence by 2-3-fold as reported [53].

\section{What causes pandemics?}

Viruses, bacteria and other microorganisms have played a vital role in life on Earth for 3.8 billion years. The vast majority are absolutely harmless, and are often essential for ecosystems and human health. Yet, a relatively few microorganisms, such as pathogenic bacteria and viruses or parasitic protozoa, can have significant negative impacts on human health. Pathogens can adapt faster, allowing them to pass from wild animals to humans and cause diseases in man which in turn will have major socioeconomic and health impacts [54].

The chances of pathogens like viruses passing from wild and domestic animals to humans may be increased by changes in human behaviour. When people about 10,000 years B.C. began to domesticate animals, grow cereal, store food, and establish farms and cities, they gradually became sedentary and commenced trade, travel and communication with each other. The growing population density in cities was likewise favourable for emergence of epidemics and pandemics which were facilitated by gradual improvements in transportation and rapid intercontinental air travel. At the same time, animal domestication created favorable conditions for animal microbes to adapt to humans such as measles, tuberculosis, and smallpox from cattle, and influenza from pigs and ducks. In more recent times, wildlife trafficking and trade, the illegal or uncontrolled trade of wild species and the unhygienic conditions under which wild and domestic species are marketed were visible [55].

Climate change and ecosystem changes have contributed much to increasing the incidence of pandemics. The growing human population and rapid increase in consumption had changed the ecosystem through activities such as deforestation and modification of natural habitats which exposes humans to new forms of microbes 
through wild animals that host them. Climate change has increased the global temperature leading to floods and forest fires which in turn has given rise to increased air pollution and floods that has changed the human - microbe interphase facilitating spread of infectious diseases [56].

\section{Future of pandemics and strategies for prevention and control}

Emerging or re-emerging infectious disease pandemics, on an average had appeared once every decade. However, the frequency between pandemics appears to be disturbingly shorter as evident with Severe Acute Respiratory Syndrome (SARS) in 2003, Influenza A H1N5 (bird flu) in 2007, H1N1 (swine flu) in 2009, Middle East Respiratory Syndrome (MERS) in 2012 and Ebola in 2014 [57]. Currently we are in the midst of a raging SARS Cov2 (COVID-19) pandemic which commenced in late 2019.

Previous pandemics can recur due to adaptation of the organisms or when the environment becomes suitable for the spread of the pathogen responsible. If one examines the example of the ancient disease, plague, it cannot be eradicated as they remain enzootic in the wild rodent reservoirs. Human cases of plague continue to occur specially in Africa and 200-300 cases are reported annually to the WHO [58]. A plague outbreak may also cause widespread panic, as occurred in India in 1994 when a relatively small outbreak, with 50 deaths, was reported in the city of Surat [59]. This led to a nationwide collapse in tourism and trade, with an estimated cost of US\$600 million [60], Yersinia pestis was recently shown to be able to acquire antibiotic resistance plasmids under natural conditions [61]. Thus, reemergence of old diseases with greater virulence represents a major threat to human health.

To overcome pandemic spread of these infections early detection is important. The integration of human, veterinary, and agriculture as proposed by the 'One Health' approach, should result in earlier warning of emerging infectious diseases and provide us with a better opportunity to respond to potential spill-over infections [62].

In April 2000, WHO formally launched the Global Outbreak Alert and Response Network (GOARN) as a mechanism to electronically link together national networks, in real time and to keep the international community alert to outbreaks and be ready to respond. By this method, the WHO could maintain close vigilance over the evolving infectious disease situation and to mobilize outbreak verification and response activities when needed. The Global Public Health Intelligence Network (GPHIN), a powerful new tool developed by Health Canada is being used by WHO since 1997 for screening networks. It picks up more than 18,000 items every day, of which around 200 merit further analysis by the WHO [63]. However, many less developed countries are not adequately prepared to respond to national epidemics, as this may not be a priority. For the systems developed to be effective, these countries need to be supported to strengthen their health systems through assistance for training, infrastructure development for prompt diagnosis and technology required for “real-time” reporting [64].

The great majority of the more recent epidemics and pandemics were zoonotic and some related to wildlife. Thus, surveillance systems on wildlife to identify the carriage of high-risk pathogens, people who have contact with wildlife to identify early spillover events and market biosecurity regarding the wildlife trade need to be established worldwide [65].

Further, the use of advances in computer science and computing speeds including artificial intelligence and data science, systems science, pathogen genomics and metagenomics need to be vigorously integrated to $21^{\text {st }}$ century epidemic responses to improve the speed of response and address multifaceted complexities when planning and responding to pandemics [66].

In conclusion, the current COVID-19 pandemic and its dreadful global impact is a reminder of the certainty of emerging infectious diseases. Fortunately, the world today, is generally better equipped to battle these emerging threats for ensuring human survival. However, the repercussions of the pandemic have led to extreme uncertainty and an unprecedented crisis in all sectors including economy, trade and health and wellbeing of people. Although it is impossible to foresee where this pandemic is heading, there is no doubt that a new chapter in the history of infectious diseases is being written.

\section{References}

1. Merriam-Webster, n.d. Web. Merriam-Webster.com. 2018 Nov 10. https://www.merriamwebster.com/dictionary/ plague (accessed 16 Apr 2021).

2. Thucydides, The history of the Peloponnesian war. trans. Crawley R. Digireads.com. 2017; 2: 89-100. https:// www.gutenberg.org/files/7142/7142-h/7142-h.htm (accessed 16 Apr 2021).

3. Littman RJ. The plague of Athens: epidemiology and paleopathology. Mt Sinai J Med. 2009; 76(5): 456-67. https://doi.org/10.1002/msj.20137. PMID: 19787658.

4. Olson PE, Hames CS, Benenson AS, et al. The Thucydides syndrome: Ebola Déjà vu? (or Ebola Reemergent?). Emerg Infect Dis. 1996 Apr-Jun; 2(2): 155-156. doi:10.3201/eid0202.960220.

5. Horgan J. Justinian's Plague (541-542 CE). World History Encyclopedia 2014 Dec 26; 1(1). https://www. worldhistory. org/article/782/ (accessed 17 Apr 2021). 
6. Rosen W. Justinian's flea: Plague, empire, and the birth of Europe. Jonathan Cape, $1^{\text {st }}$ ed. 2007 May 3.

7. Procopius, History of the wars. trans. Dewing HB. Loeb Library of the Greek and Roman Classics. Cambridge, MA: Harvard University Press 2014; 1: 451-73.

8. The Editors of Encyclopaedia Britannica. Black Death. Encyclopedia Britannica 2018 Sep 4; 1(1).

https://www.britannica.com/event/Black-Death (accessed 17 Apr 2021).

9. Hatcher J. The Black Death: an intimate history. London: Weidenfeld \& Nicolson 2010 Dec 30.

10. Boccaccio G, The Decameron. trans. Rigg M. London: David Campbell 1921; 1: 5-11.

11. Gottfried RS. The black death: natural and human disaster in medieval Europe. Simon and Schuster 2010; 74-75.

ISBN 978-1-4391-1846-7.

12. Hajar R. The air of history (Part II) medicine in the middle ages. Heart Views 2012; 13(4): 158-62. doi: 10.4103/1995-705X.105744.

13. Scheidel W. The great leveler: violence and the history of inequality from the stone age to the twenty-first century. Chapter 10: the black death. Princeton: Princeton University Press 2017;

doi: 291-313. ISBN 978-0691165028.

14. Boeckl CM. Images of plague and pestilence: iconography and iconology. Kirksville: Truman State University Press 2000; $27:$ 14-15.

15. Sehdev PS. The Origin of Quarantine. Clin Infect Dis. 2002; 35(9): 1071-2. doi: https://doi.org/10.1086/344062. PMID 12398064.

16. Huang B, Li G, Li F, et al. The 1855 to 1859 locust plague in China. Natural Hazards 2019; 95(23): 529-545. doi:10.1007/s11069-018-3498-2.

17. Abedi AA, Shako J, Gaudart J. Ecologic Features of Plague Outbreak Areas, Democratic Republic of the Congo, 20042014. Emerg Infect Dis. 2018, Feb; 24(2): 210-220. doi: 10.3201/eid2402.160122.

18. Antonovics J, Hood ME, Baker CH. Molecular virology: was the 1918 flu avian in origin? Nature 2006; 440(7088): E9, discussion E9-10. doi: 10.1038/nature04824.

19. Flecknoe D, Charles Wakefield B, Simmons A. Plagues \& wars: the 'Spanish flu' pandemic as a lesson from history. Med Confl Surviv. 2018; 34(2): 61-8. doi: 10.1080/13623699.2018.1472892. Epub 2018 May 15.

20. Langford CM, Storey P. Influenza in Sri Lanka, 1918-1919: the impact of a new disease in a premodern Third World setting. Health Transition Review 1992; 2(2): 97-122.

21. Dawood FS, Iuliano AD, Reed C, et al. Estimated global mortality associated with the first 12 months of 2009 pandemic influenza A H1N1 virus circulation: a modelling study. Lancet Infect Dis. 2012; 12(9): 687-95.

doi: 10.1016/S1473-3099(12)70121-4.

22. Garske T, Legrand J, Donnelly CA, et al. Assessing the severity of the novel influenza A/H1N1 pandemic. BMJ. 2009 Jul 14; 339: b2840. doi: 10.1136/bmj.b2840.

23. World Health Organization(WHO). Smallpox vaccines 2016 May 31.

https://www.who.int/news-room/feature-stories/detail/ smallpox-vaccines (accessed 27 Apr 2021).

24. Fears JR. The plague under Marcus Aurelius and the decline and fall of the Roman Empire. Infect Dis Clin N Am. 2004; 18(1): 65-77. doi: 10.1016/S0891-5520(03)00089-8.

25. Sabbatani S, Fiorino S. The Antonine Plague and the decline of the Roman Empire. Infez Med. 2009 Dec; 17(4): 261-75. PMID: 20046111.

26. Ilic M, Ilic I. The last major outbreak of smallpox (Yugoslavia, 1972): A reminder. Travel Med Infect Dis. 2017; 17: 69-70. doi: 10.1016/j.tmaid.2017.05.010. Epub 2017 May 22.

27. Lippi D, Gotuzzo E. The greatest steps towards the discovery of Vibrio cholera. Clin Microbiol Infect 2014; 20: 191-5. doi: 10.1111/1469-0691.12390. Epub 2013 Nov 6.

28. Guerrant R, Cameiro-Filho B, Dillingham R. Cholera, Diarrhea, and Oral Rehydration Therapy: Triumph and Indictment. Clin Infect Dis. 2003 Aug 1; 37(3): 398-405. doi: 10.1086/376619. Epub 2003 Jul 22.

29. Wang H, Wolock TM, Carter A, et al. Estimates of global, regional, and national incidence, prevalence, and mortality of HIV, 1980-2015: The Global Burden of Disease Study 2015. The Lancet HIV 2016; 3(8): e361-87. doi: 10.1016/s2352-3018(16)30087-x.

30. HIV and AIDS - Basic facts. UNAIDS. https://www.unaids. org/en/frequently-asked-questions-about-hiv-and-aids (accessed 27 Apr 2021).

31. World Health Organization (WHO). Severe Acute Respiratory Syndrome (SARS).

https://www.who.int/health-topics/severe-acuterespiratory-syndrome\#tab=tab_1 (accessed 28 Apr 2021).

32. Smith RD. Responding to global infectious disease outbreaks: Lessons from SARS on the role of risk perception, communication and management. Soc Sci Med. 2006; 63(12): 3113-23. doi: 10.1016/j.socscimed. 2006.08.004.

33. World Health Organization (WHO). Summary of probable SARS cases with onset of illness from 1 November 2002 to 31 July 2003.

https://www.who.int/publications/m/item/summary-ofprobable-sars-cases-with-onset-of-illness-from-1november-2002-to-31-july-2003. (accessed 27 Apr 2021). 
34. Zaki AM, Boheemen SV, Bestebroer TM, et al. Isolation of a novel coronavirus from a man with pneumonia in Saudi Arabia. N Engl J Med. 2012 Nov 8; 367(19): 1814-20. doi: 10.1056/NEJMoa1211721.

35. World Health Organization (WHO). Middle East respiratory syndrome.

http://www.emro.who.int/health-topics/mers-cov/mersoutbreaks.html (accessed 28 Apr 2021).

36. Memish ZA, Mishra N, Olival KJ, et al. Middle East Respiratory Syndrome Coronavirus in Bats, Saudi Arabia. Emerg Infect Dis. 2013; 19(11): 1819-1823.

37. Mubarak A, Alturaiki W, Hemida MG. Middle East Respiratory Syndrome Coronavirus (MERS-CoV): Infection, Immunological Response, and Vaccine Development. Journal of Immunology Research 2019; 1-11. doi: 10.1155/2019/6491738.

38. Coltart CEM, Lindsey B, Ghinai I, et al. The Ebola outbreak, 2013-2016: old lessons for new epidemics. Philos. Trans R Soc. Lond B Biol Sci. 2017 May 26; 372(1721): 20160297. doi: 10.1098/rstb.2016.0297.

39. Kalra S, Kelkar D, Galwankar SC, et al. The emergence of ebola as a global health security threat: from 'lessons learned' to coordinated multilateral containment efforts. J Glob Infect Dis. 2014 Oct; 6(4): 164-177. doi: 10.4103/0974-777X.145247.

40. Kindhauser MK, Allen T, Frank V, et al. Zika: the origin and spread of a mosquito-borne virus. Bulletin of the World Health Organization (WHO) 2016 Sep 1; 94(9): 675-686C. doi:10.2471/blt.16.171082.

41. Wood MJ. Propagating and Debunking Conspiracy Theories on Twitter During the 2015-2016 Zika Virus Outbreak. Cyberpsychology, Behavior, and Social Networking. 2018; 485-490.

doi:10.1089/cyber.2017.0669. Epub 2018 Jul 18.

42. World Health Organization (WHO). WHO Coronavirus (COVID-19) Dashboard.

https://covid19.who.int/?adgroupsurvey (accessed $23 \mathrm{Apr}$ 2021).

43. COVID-19 routes of transmission - what we know so far. Public health Ontario, 2020 Jan 12.

https://www. publichealthontario.ca/-/media/documents/ ncov/covidwwksf/2020/12/routes-transmission-covid19.pdf?la=en (accessed 26 Apr 2021).

44. Epidemiology Unit. Guidance for workplace preparedness for COVID-19. Ministry of Health \& Indigenous Medical Services 2020 Mar 15. https://www.epid.gov.lk/web/images/ pdf/Circulars/Corona_virus/guidance $\% 20$ for\%20w orkplace\%20preparedness\%20for\%20covid\%20version\% 202.pdf (accessed 27 Apr 2021).

45. Bhat RA, Qadri SA, Muhee A. Importance of preventive measures in tackling COVID -19. International Journal of Avian \& Wildlife Biology 2020 Nov 9; 5(1): 23-25.
46. Skegg D, Gluckman P, Boulton G, et al. The Lancet 2021 Feb 27; 397(10283):1419-1518.

https://mwww.thelancet.co/journals/lancet/issue/ vol397no10283/PIIS0140-6736(21)X0016-5 (accessed 24 Apr 2021).

47. Maunder RG. Was SARS a mental health catastrophe? Gen Hosp Psychiatry. 2009; 31(4): 316-7. doi: 10.1016/j.genhosppsych.2009.04.004. Epub 2009 May 22.

48. Torales J, O'Higgins M, Castaldelli-Maia JM, et al. The outbreak of COVID-19 coronavirus and its impact on global mental health. International Journal of Social Psychiatry 2020; 66(4), 317-320. doi: 10.1177/0020764020915212.

49. Mohmmed AO, Khidhir BA, Nazeer A et al. Emergency remote teaching during Coronavirus pandemic: the current trend and future directive at Middle East College Oman. Innov Infrastruct Solut. 2020; 5(3): 72. doi: 10.1007/s41062-020-00326-7.

50. World Health Organization (WHO). Prevention and promotion in mental health. Department of mental health and substance dependence 2002. https://www.who.int/ mental_health/media/en/545.pdf (accessed 27 Apr 2021).

51. Cheval S, Adamescu CM, Georgiadis T, et al. Observed and Potential Impacts of the COVID-19 Pandemic on the Environment. Int. J. Environ. Res. Public Health 2020; 17(11): 4140. doi:10.3390/ijerph17114140.

52. Roger S. BULLETIN: Civil Rights, HIPAA, and the Coronavirus Disease 2019 (COVID-19). Jpn J Infect Dis. 2015; 589: 125-128.

53. Oliveira AFL, Rishal P, Johnson M. Domestic violence during the pandemic. BMJ 2021 Mar 17; 372:n722. doi: 10.1136/bmj.n722.

54. Pike BL, Saylors KE, Hair JN, et al. The origin and prevention of pandemics. Clin Infect Dis. 2010 Jun 15; 50(12): 1636-1640. doi: 10.1086/652860.

55. Levitt T. Covid and farm animals: nine pandemics that changed the world. Animals farmed environment 2020 Sep 15. https://www.theguardian.com/environment/ng-interactive/ 2020/sep/15/covid-farm-animals-and-pandemics-diseasesthat-changed-the-world (accessed 28 Apr 2021).

56. Jenkins A, Jupiter SD, Capon A. Nested ecology and emergence in pandemics. The Lancet Planetary Health 2020; Aug 1; 4(8): E302-E303. doi: 10.1016/S2542-5196(20)30165-0.

57. Jones KE, Patel NG, Levy MA, et al. Global trends in emerging infectious diseases. Nature 2008 Feb 21; 451(7181): 990-993. doi: 10.1038/nature06536.

58. World Health Organization (WHO). Human plague in 2002 and 2003. Weekly Epidemiological Record = Relevé épidémiologique hebdomadaire. 79(33): 301-306. https://apps.who.int/iris/handle/10665/232559 (accessed 29 Apr 2021). 
59. Mudur G. India's pneumonic plague outbreak continues to baffle. BMJ 1995 Sep 16; 311(7007):706. doi: 10.1136/bmj.311.7007.706a. PMID: 7549679.

60. Fritz CL, Dennis DT, Tipple MA, et al. Surveillance for pneumonic plague in the United States During an international emergency: A model for control of imported emerging diseases. Emerg Infect Dis. 1996 Jan-Mar; 2(1): 30-6. doi: 10.3201/eid0201.960103. PMID: 8964057.

61. Galimand M, Guiyoule A, Gerbaud G, et al. Multidrug resistance in Yersinia pestis mediated by a transferable plasmid. N Engl J Med 1997 Sep 4; 337(10): 677-80. doi: 10.1056/NEJM199709043371004.

62. Childs JE, Gordon ER. Surveillance and control of zoonotic agents prior to disease detection in humans. Mt Sinai J Med 2009 Oct; 76(5): 421-8. doi: $10.1002 / \mathrm{msj} .20133$.

63. World Health Organization (WHO), Communicable Disease
Surveillance and Response. Severe Acute Respiratory Syndrome (SARS): Status of the outbreak and lessons for the immediate future. Geneva 2003 May 20.

https://www.who.int/csr/media/sars_wha.pdf (accessed 29 Apr 2021).

64. Oshitani H, Kamigaki T, Suzuki A. Major Issues and Challenges of Influenza Pandemic Preparedness in Developing Countries. Emerg Infect Dis. 2008 June; 14(6): 875-880. doi: 10.3201/eid1406.070839.

65. Daszak P, Olival KJ, Li H. A strategy to prevent future epidemics similar to the 2019-nCoV outbreak. Elsevier 2020 Mar; 2(1): 6-8. doi: 10.1016/j.bsheal.2020.01.003.

66. Bedford J, Farrar J, Ihekweazu C, et al. A new twenty-first century science for effective epidemic response. Nature 2019 Nov 6; 575: 130-136. doi:10.1038/s41586-019-1717-y. 